of modifying the functions of the nervous posterius, and anterior condyloid forasystem, has been used, and it is said with men of the left side, compressing (succesbenefit, in the dose of from three to ten grains daily. Its virtue was particularly vaunted by lissot. Sec the Archives, vol. 19. In the Ephémérides de Montpelier; t. 3, are some cases successfully treater by the meadow narcissus. Opium is of use also in cases where obvious indications exist for its administration. Orange flowers in infusion, or powder, to the amount of half an ounce daily. The acetate of lead from one-half to six grains. The prussiate of iron, see Revue Médicale, t. 3, 1827. Quinine in the distinctly periodical cases; rhue succinate of ammonia; the sedum acre; stramonium (see Bulletin Thérapeutique, t. 1) ; strychnine, (Revue Médicale, 1827) ; turpentine, which M. Foville, a sceptic about all remedies in this disease, found to succeed in one case; rinc in oxide, and chloruret valerian, in which Tissot reposed much confidence,-all these have been tried, and generally with disappointment. Respecting the last remedy mentioned, M. Chauffard of Avignon relates a case in which the disease seemed to he excited by masturbation. The valerian was given in doses of from two to four drachms daily, and the epilepsy ceased while the remedy was used. It should not be lost sight of, however, that the habit of masturbation was desisted from at the same time.

The principal memoirs you can consult with advantage respecting this disease, besides the works to which I have already referred, are the work by M. Bertin, the article by M. Esquirol in the Dictionnaire des Sciences Medicales the Thesis of M. Calmeil, an article by M. Bouchet in the Archives Générales, 1828, and the Thesis of M. Braset, Paris, 1827.

\title{
REMARKABLE CASE
}

OF

\section{PATHOLOGICAL PHYSIOLOGY}

IN THE HUMAN SUBJECT.

By H. Montault, D.M.P., \& c., Surgeon to the Sixth Dispensary of the "Societe Philanthropique*."

Analysis of Pathological Characters. Hydatid cyst, developed externally to the bony substance, and within the cavity formed by the base of the skull, penetrating into the foramen lacerum

* Vide Jonernal Hebdomadaire, March 31, 1853, and Lancet, No. 001, page 62 sively) the hypoglossal, glosso-pharyngeal, spinal, and pneumo-gastric nerves, the cerebellum, the meso-cephalon, and the upper part of the spinal chord of the corresponding side. Excessive accumulation of fiuid in the ventricles of the brain.

Analysis of Concomitant Phenomena.-Paralysis and atrophy of the muscles of the left side of the tongue; preservation of taste on this side (the lingual nerve being intact); paralysis of the tongue in the articulation of sounds; 'pain in the corresponding side of the neck: paralysis of the organs of deglutition and of voice; epileptiform paroxysms; atrophy of the muscles of the velum palati and left corda vocales; general lesion of sensibility; falling of food into the air-passages; death.

It has been repeatedly said, that " medicine is but the physiology of man in a state of disease." Never was a theory better supported than by the following facts, which I proceed to expose in their minutest details, before proceeding to derive from them the deductions and numerous applications they afford in the study of normal physiology. So many accidents, dificulties, and complications, prevent our illustrating this study by experiments on living animals, that I regard the subsequent case as a fortunate event for those engaged in experimental physiology. Before proceeding any further, I am bound to express my gratitude to MM. Dupuytren, Gendrin, and Rostan, who have permitted me to avail myself freely of the facts in question.

A man named Girard, xt. 33, a weaver, having worked a long time in a low and damp situation, and been, consequently, exposed to rheumatic affections, about three years since experienced extreme pain at the posterior and lateral part of the left side of the head. Having lasted fifteen days, the pain then extended to the corresponding side of the neck, causing sleeplessness, anil embarrassing the movenents of the head, accompanied by trembling and shooting of the muscles of this region. According to the patient's statement, these pains followed closely on an accident, he having struck the back part of his neck on falling down a long flight of stairs. To the pain soon succeeded a dificulty of enunciation, but there was no symptom of paralysis of the left side of the face. The application of leeches, \&c., procured some abatement of 
the pain, which disappeared even at the ceived into M. Gendrin's wards* in a state end of a year, but soon returned (less se- much worse than before. On February verely), and thus continued until Septem- 14th, 1832, he was somewhat better; no ber 1831, when it became much more pain in the face, but much in the neck, intense at the upper and back part of the especially behind the ears, on a level with neck, so as completely to preclude any the posterior and lower part of the masmovement of the head. In October of the same year, he was admitted into the Salle Saint Marthe, under the charge of $M$. Dupuytren, who at that time made the following remarks on his condition:-The movements of flexion, whether lateral or antero-posterior, are partly executed by the entire of the vertebral column. The tongue is diminished in volume, and atrophied at its left side alone; more so at the point and middle than at its base. This circumstance the patient noticed from the commencement of his illness. The right side of the tongue seemed larger and stronger than usual. The left side was reduced almost to the thickness of its mucous envelope. The articulation of sounds, difficult at first, was now clear and distinct-a circumstance apparently more the result of exercise in speaking, than of a diminution of the disease. By successive applications of four different substances-sugar, sulphate of quinine, $\mathrm{mu}$ riate of soda, and acids dissolved in a small quantity of water, any changes which might supervene in the sense of taste were carefully noted. The results of these experiments, previously performed on healthy persons, left no doubt that tastes were perceived by the left side of the tongue.

Proceerling hy the mode of exclusion, it was easy to conclude, that of the three nerves distributed to the tongue, the hypoglossal, glosso-pharyngeal, and lingual, that of the ninth pair, the hypoglossal should necessarily be altered. The absence of general paralysis, contractions, convulsions, or deranged intelligence, moreover, led M. Dupuytren to admit a lesion of this nerre at its exit from the skull, and not at its origin. As to the nature and species of this lesion, M. Dupuytren suspected that a chronic and rheumatic engorgement of the ligaments unit. ing the first vertehra and the occiput, might have compressed, or altered, the tissue of the hypoglossal nerve, which escapes by the anterior condyloid foramen. He thought, also, that below the point of its exit the nerve was only atrophied, whence the corresponding paralysis and atrophy of the left side of the tongue.

In a month after this the man left the hospital, but returned again in a few days; again, however, he went home, and a third time returned to the Hotel Dieu (in Decemuer 1831), when he was reto follow the nervous filaments of this part. The patient now stated that all his senses were perfect, but that the venereal appetite had sensibly declined for the past three months. On the 10th of February, the experiments of $M$. Dupuytren on the tongue were repeated, and with the same results. The patient now complained that he occasionally experienced peculiar sensations of trembling, of sharp blows on the skin at both sides, on the shoulders, abdomen, and cheeks. On the 24th of March he again left the Hotel Dieu, and returned to M. Rostan's wards on the 28th of the following September. Attentive examination was now made as to his condition, which we proceed to describe:-

Pain towards the occipital opening, extending to the $3 \mathrm{rd}$ or 4 th cervical vertebra, but permanently fixed on a level with the articulation of the atlas and axis, without swelling or alteration in the texture or colour of those parts. Behind the mastoid apophysis of the same side there is a small tumour of the size of a franc, elevated about two lines ahove the surface, almost circular, hard, slightly painful on moderate compression, not surrounded by a bony prominence-as we observe in cases of fungi of the dura mater, which have perforated the cranium. Very strong compression causes intense pain, which extends to the origin of the rachidian canal. The sonorousness and clearness of the voice are altered, but the pronmciation is not difficult. No cough or expectoration. The intellect intact, but the patient consirlers his memory gradually to have declined for the last month. Deglutition imperfect; fluids always penetrate the larynx in small quantities, but solids are swallowed without difficulty. Digestion good; slight constipation ; urinary secretion normal. Some torpor of the left arm, but none in the corresponding lower extremity. The patient can, nevertheless, move the arm with perfect precision. No fever. M. Rostan now expressed his belief that the disease was a fungous tumour of the dura mater at the base of the brain.

From the 8th October the patient experienced hiccups; disgust for food; vomiting without any other symptom or

*We omit all details of treatment, \&c., with which M. Montault has needlessly encumbered this valuable case, as they are destutule of the slightest interest.-ED.j 2 
gastritis; obstinate constipation. The hiccup returned on the least movement, and was in vain treated by the acetate of morphine. Fever also every evening. The disease now progressed rapidly, and, affected by sinister ideas, he left the hospital on the 6th November. On the 20th December he was received again under M. Gendrin's charge in the Hôpital Cochin. The following additional symptoms were then noted. Almost complete uphonia; diminished sensibility of the entire of the left side; scanty secretion of urine; general emaciation; skin dry; memory enfeebled. He is fatigued when questioned; appetite impaired; fever; and want of sleep.

25th December. Voice weaker than ever; the lungs of the left side have become the seat of prickings and lancinations. Intense suborbitar pain; great thirst; tongne slightly red; deglutition of liqui.ls more difficult; incoluntary and unconscious discharge of urine and fæces; total loss of memory; pulse very frequent; skin hot. A confluent and aphthous eruption appeared in a few days after this, which was removed by detersive gargles. From the 1st to the 8th January 1833, there were cough and abundant expectoration, and considerable embarrassment of deglutition, but on the 8th January, this symptom surdenly increased to such a pitch, that the patient was threatened with suffocation every moment; the intellect was still intact. On the 12th January, after swallowing a few spoonfuls of bouillie, he fell back on his pillow and died. For several days before his death, some epileptiform paroxysms had been noticed, and deglutition became so difficult, that he spent entire hours in sucking up a spoonful of bouillie.

\section{Examination of the Body twenty-four hours} after Death.

External Appearance.-No cadaveric rigidity; considerable emaciation.

Head.*-The pulp of the brain rather firmer than usual, and the ventricles dilated "by a great quantity of serum. In lifting out the cerebellum, a cyst was perceived (having whitish, opaque, slightlyresisting sides, about half a line thick), in volume equal to a goose's egg. presenting manifest fluctuation. Being casually opened, there escaped a quantity of limpid serum, and a multitude of hydatids, perfectly sound, smooth, and transparent, varying in size from that of a grain of millet seed to a chestnut.

* We omit from M. Montault's tedious and unnecessary details, everything which presented no morbid deviation, -ED. L:
This cyst was placed between the left occipital fossa, the corresponding side of the basilary surface, the left hemisphere of the cerebellum, which it lifted up, and the rachidean bulb, which it pushed slightly to the right side. It adhered to none of these parts, which preserved the hrightness of their arachnoid covering, even where in contact with the tumour, so that this seemed as if free in the carity of that tnembrane. It penetrated to the depth of some lines into the rachidian canal, and on a level with this point, there proceeded from it a sort of appendix, shaped like the finger of a glove, penetrating the anterior condyloid foramen, and containing a hydatid. From the base of the cyst again proceeded another, still more remarkablc, appendage, which engaged itself in the anterior portion of the left posterior foramen lacerum, and, turning from before backwards, after traversing this opening, as it passed behind the bundle of muscles known by the name of the "Bouquet anatomique de Riolan," dilated into a bulbous form, as far as the superior extremity of the complexus and sterno-mastoid muscles. This second cyst, or prolongation of the first, had white, opaque, and soft sides. It was, the size of a large nut, covered externally by a fibro-cellular fold, by the digastric muscle, the mastoid apophysis, and the superior extremities of the plexus and sterno-mastoid nuuscles. This, in fact, was the cyst, the presence of which had been ascertained during life, during the patient's treatment by M. Rostan at the Hotel Dieu. It contaired numerous hydatids, and communicated with the intra-cranial cyst already described. The narrow structure by which they communicated corresponded with the posterior foramen lacerum.

It became of great importance to examine the nerres proceeding from the hase of the cranium. The lingual nerves were perfectly sound. The glosso-pharyngeal and pneumogastric nerves of the left side differed in no respect from those of the right side, from their origin to their passage into the foramen lacerum posterius, but immediately after their issue from this opening, their condition differed individually. The hypoglossal nerve, or the 9 th, also was unatfected from its origin to its exit from the foramen lacerum anterius, but from that point it was in a state of atrophy, reduced to the dimensions of a thread, two-thirds at least less in size than the nerve of the right side. This atrophy continued all along to the minutest ramifications among the muscles of the tongue. It appeared to be the result of the compression exercised by the little appendix sent off from the intra-cranial cyst through the anterior condyloid foramen. The 
glosso-pharyngeal, spinal, and pneumogastric nerves had also been crmpressed by the same cyst in the foramen lacerum posterius; however, the glosso-pharyngeal th was the only one of these nerves which was smaller (by one-third) than those of the opposite side.

The bones in contact with, or pressed upon by, the cysts here described, were absorbed to a considerable extent, as is seen in cases of aneurism pressing on bony parts.

Organs of Deglutition.-At the left side, the muscles, whether intrinsic or external to the tongue, were totally thinned, pale, atrophied; their fibres few, yellowish, and soft, having the aspect of a spongy tissue, devoid of the traces of their primitive organization. Pharynx nothing remarkable; cesophagus strongly contracted, but not altered in structure.

Organs of Vrice.-Considerable quantities of bouillie in the larynx; considerable paleness of the larynx; atrophy of the left corda vocalis; trachea bright red, and its mucous lining swollen.

Thoracic viscera, heart, stomach, intestines, and bladder, quite normal. The hepatic veins much distended, and below the middle lobe there was a smooth white tumour, containing hydatids of variable volume. The vertehræ, spinal column, and its membranes, perfectly healthy.

$$
\text { lieflealions. }
$$

It seems to me, that the hest manner of illustrating the interest of this case, is by placing exactly in juxta-position with each other, the symptoms preserted by the patient, and the alteralions found after his death. The principal phenomena, then, which the malady of Gerard presented, were the following, in the order of their appearance :-

1. Yain at the posterior and lateral part of the left side of the head and neck. May we not refer this pain to the development of the external hydatid pouch, which must have compressed, from within outwards, the extremities of the complexus and sterno-mastoid muscles, and to the compression, by the internal cyst, of the spinal nerve in the posterior foramen lacerum ?

2. Extreme difficulty of pronunciation, depending on a loss of power of movement in some of the muscles of the tongue. But what nerve was here concerned? The glosso-pharyngeal, which was compressed and dininished in volume. Charles Bell, as is known, has classed this among the respiratory nerves, giving us thereby to understand, that it contributes to movements in relation with the external phenomera of expression of the individual. M. Manec, in his plates of the origins of the nerves, has confirmed, in this respect, the researches of Charles Bell, by stating that this nerve concurs in the movements of the tongue in the pronunciation or articulation of sounds, while the movements in mastication are influenced by the great hypoglossal.

3. Paralysis and atrophy of the left side of the tongue, without loss of taste. The atrophy of the hypo-glossal nerve, and the perfect state of the lingual nerve of the same side, will explain this two-fold circumstance. This fact, then, would prove also, that the trifacial by the lingual branch, presides over the faculty of perceiving or tasting flavours. Despite the great number of experiments undertaken to discover to which of the three nerves that distribute themselves to the tongue we are to attribute this property, definitive experiments have until lately been wanting; but at present they abound, so as to place beyond doubt that this property belongs to the lingual branch. The following facts prove this statement. The lingual branch of the 5th pair distributes itself to the papillæ of the tongue. In the lower animals, in which only one organ of sense, and that the taste; is to be detected, the tongue is supplied by the branch in question. According to Casserius, Scarpa, Jacobson, Dumeral, Treviranus, Weber. Magendie, Serres, and De Blainville, the lingual branch may assist, replace, or act for the gustatory nerve. According to Galien, Willis, Vieusseus, Rassener, Gall, and Belingeri, taste has also been referred to the same branch; and, lastly, in modern times, several experinents and cures have corroborated this opinion. By means of galvanism, indeed, MMI. Dupuytren and Richerand have demonstrated the lingual to be the nerve of taste. The delicate experiments of M. Magendie, who paralysed the sense of taste by cutting the 5th pair in animals, and the beautiful case related by $M$. Serres, in which taste was lost during an alteration of the trifacial, (a case by-the-by to which ours forms the counterproof,) concur in the same indications. This atrophy and paralysis of one side of the tongue, with preservation of taste, is, moreover, of high importance, since it confirms the law announced by M. Serres, and supported by Geoffroy St.-Hilaire, that every organ of the special senses receives two principal nerves, one which keeps up the harmony and conservation of the fonstituent parts of the organ, another which contributes directly to sensation, as the comluctor of the impression to the brain.

4. Lesion of general sensibility, first in the left side, and then in both sides. I believe this to have depended on the compression by the internal cyst, either of the 
superior part of the medulla oblongata Dupuytren, Blainville, Brodie, Legallois, backwards, or rather of the meso-cephalon, Dupuy, D's lfort, Magendie, Wilson Philwhich the examination showed to have lip, Dumas, Leuret, and Lassaigne, Bresbeen much displaced.

5. Paralysis of the organs of deglutition. Explained by the compression and diminished volume of the glosso-pharyngeal nerve.

6. Loss of memory and weakened venereal appetite. These facts are interesting to those who regard the cerebellum as the seat of one or other of the two faculties, a part of it having been compressed by the cyst.

7. Torpidity and commencing paralysis of the left arm; obstinate constipation. This appears to me to be the result of compression on the upper part of the medulla, or medulla oblongata. It is remarkable, too, that all the functional troubles resulting from the compression, whether of the nerves or nervous masses, showed themselves always at the same side as the lesion of the nervous system described in the preceding columns; a fact which accords with our previous physiological knowledge, since the lesion occurred in a part of the nervous system placed below the origin of the nerves. This remark does not apply to the alterations of the general sensibility produced by the compression of the annular protuberance.*

8. Hiccup, aphonia, fall of food into the air-passages; death. All these events appear to me, as well as the atrophy of the thyro-arythenoid muscle, and of the left side of the velum palati, to have been produced by the same lesion, namely, the compression of the pneumo-gastric nerve in the foramen lacerum posterius,-death being immediately caused by the asphyxia produced by the food which fell into the trachea and bronchial tubes. I think so, because similar accidents follow the section of this nerve at a certain height, or even the section of some of its branches, such as the superior laryngeal and recurrent. It was thus that Galien observed the voice to be lost by the division of the recurrent; that Legallois, Desmouslins, and Dumas, have proved that asphyxia then takes place by occlusion of the glottis; that M. Cruveilhier has ascertained the extinction of the voice to have resulted from compression of the recurrent nerves by an aneurism of the aorta. Additional facts of this kind may be found in the writings of Galien, Picolhomini, Lower, Boyce, Willis, Valsalva, Haller,

- M.Montault here enters upon some ingenious peculations relative to the cause of the epileptiform accessions. They are, however, too purely theoretical, to be coupled with the preceding lacts and deductions. Moreover, M. Gendrin believes the paroxysms to have been rather lethargic than epileptic.-ED. L. chet, Milne, Edwards, and Vavasseur, Abel and Hastings, Lahoumes, Broughton, Bichat, Desmoulins, Tiedemann, Gmelin, and Sedillot.

[M. Montault concludes his case by citing some others by no means so interesting or so well calculated to elucidate the functions of the nervous system.].

$-$

LITHOTRITY.

CASE OF STONE IN THE BLADDER, FROM INJURY TO THE LOINS.-MENINGITIS.

By W. B. Costello, Esq., Surgeon.

Some years ago the subject of this observation, J. Collinson, Esq., of Brantfell, Bowness, (Westmoreland,) had a fall from his horse. $U_{p}$ to that period he had always enjoyed excellent health. When a young man he used to indulge in all the manly sports of his native county, and even at the time of the accident, though he had passed his fiftieth year, he was still remarkable for the activity of his habits. He was thrown with violence on his loins, and although every attention was paid that skill could suggest under the circumstances, the lumbar region continued to be the seat of an aching pain, which made him very uncomfortable. His urine was: bloody for a little time after the accident. About two years later he consulted a surgeon, on account of some irregularity in the excretion of his urine; his medical adviser combated the notion of his having a stone, but $\mathrm{Mr}$. Collinson was satisfied that he had, relying for the correctness of his opinion on what he suffered when riding. or exerting himself, and on his sensations: of a foreign body against the neck of the bladder. His general health, however, had remained unaltered.

I operated on him at Ambleside on the 28 th $J$ une, 1830, in the presence of Messrs. Carr and Fell, surgeons of that place. The urethra was small, the bladder healthy; the stone was easily felt and seized; it was flat, and measured three-fourths of an inch in the diameter through which the drill passed. The sitting lasted three minutes, and some powder and fragments were scon after voided; among the latter was one which proved the flatness of the stone.

He walked abont the town after this operation, and did not seem to suffer in any way. A few days later, when I was about to resume the sittings, I observed that he appeared wild and fatigued, though he complained of no pain whatever in the 